\title{
The Role of Social Media in the Advent of COVID-19 Pandemic: Crisis Management, Mental Health Challenges and Implications
}

\author{
Jaffar Abbas $\mathbb{D}^{1,2}$ \\ Dake Wang (iD ${ }^{2}$ \\ Zhaohui Su $\mathbb{D}^{3}$ \\ Arash Ziapour (iD ${ }^{4}$
}

'Antai College of Economics and Management (ACEM), Shanghai Jiao Tong University (SJTU), Shanghai, 200240, People's Republic of China; ${ }^{2}$ School of Media and Communication (SMC), Shanghai, Shanghai Jiao Tong University (SJTU), 200240, People's Republic of China; ${ }^{3}$ School of Nursing, University of Texas, Center on Smart and Connected Health Technologies, Mays Cancer Center, UT Health San Antonio, San Antonio, TX, 78229, USA; ${ }^{4}$ Research Center for Environmental Determinants of Health (RCEDH), Health Institute, Kermanshah University of Medical Sciences, Kermanshah, 67I5847/4I, Iran
Correspondence: Dake Wang: Jaffar Abbas

School of Media and Communication

(SMC), Shanghai, Shanghai Jiao Tong

University (SJTU), 200240, People's

Republic of China

Email dakewang@sjtu.edu.cn;

Abbas5I2@sjtu.edu.cn
Background: This study focuses on how educating people through social media platforms can help reduce the mental health consequences of the COVID-19 to manage the global health crisis. The pandemic has posed a global mental health crisis, and correct information is indispensable to dispel uncertainty, fear, and mental stress to unify global communities in collective combat against COVID-19 disease worldwide. Mounting studies specified that manifestly endless coronavirusrelated newsfeeds and death numbers considerably increased the risk of global mental health issues. Social media provided positive and negative data, and the COVID-19 has resulted in a worldwide infodemic. It has eroded public trust and impeded virus restraint, which outlived the coronavirus pandemic itself.

Methods: The study incorporated the narrative review analysis based on the existing literature related to mental health problems using the non-pharmaceutical interventions (NPIs) approach to minimize the COVID-19 adverse consequences on global mental health. The study performed a search of the electronic databases available at PsycINFO, PubMed, and LISTA. This research incorporates the statistical data related to the COVID-19 provided by the WHO, John Hopkins University, and Pakistani Ministry of Health.

Results: Pakistan reported the second-highest COVID-19 cases within South Asia, the fifthhighest number of cases in Asia after Iran, India, Russia, Saudi Arabia, and the 14th highest recorded cases, as of October 14, 2020. Pakistan effectively managed the COVID-19 pandemic in the second wave. It stands at the eighth-highest number of confirmed cases in Asia, the 3rd-highest in South Asia, and the 28th-highest number of established patients globally, as of February20, 2021.

Conclusion: The COVID-19 has resulted in over 108.16 million confirmed cases, deaths over 2.374 million, and a recovery of 80.16 million people worldwide, as of February 12, 2021. This study focused on exploring the COVID-19 pandemic's adverse effects on global public health and the indispensable role of social media to provide the correct information in the COVID-19 health crisis. The findings' generalizability offers helpful insight for crisis management and contributes to the scientific literature. The results might provide a stepping-stone for conduct future empirical studies by including other factors to conclude exciting developments.

Keywords: mental health, COVID-19, health crisis, social media, social support, teleeducation

\section{Introduction}

Human civilizations have experienced various severe health problems because of the changes in the standard quality of earth, water, sky, air, and fire, which adversely affected humans' wellbeing and health in different societies 
worldwide. ${ }^{1-5}$ Since civilizations' birth, humans encountered various epidemics and pandemics, which caused panic, destruction, morality, and mental health issues. ${ }^{6-9}$ The outbreak of epidemics affects regions, while the pandemics effects are global and cause adverse consequences in spreading diseases. The history of virology identified the first virus, named the tobacco mosaic virus, in 1892. ${ }^{10-14}$ The viruses have kept evolving since then in virology literature by incorporating sophisticated microscopes. ${ }^{15,16}$ The world has become like a global village, and surveillance of the emergence and reappearance of regional epidemics or global pandemics rapidly spread transmittable diseases. ${ }^{17-19}$ The novel coronavirus infectious disease is an ongoing explicit strain of the infection of COVID-19, which has caused severe acute respiratory syndrome coronavirus-2 (SARS-CoV-2) worldwide. ${ }^{20-22}$ The coronavirus pandemic originally appeared in Wuhan city in late December $2019 .^{23,24}$ The epidemic rapidly started spreading in other cities in China. Later COVID-19 affected more than 200 countries and stated around the world. $^{25-27}$ The World Health Organization declared the COVID-19 pandemic as the Public Health Emergency as the "International Concern" on January 30 and an epidemic on March 11, 2020. ${ }^{28-30}$ Based on the statistical facts, the mortality rate among patients with infectious disease (SARS-CoV-2) ranges between $2 \%$ to $3 \%$ worldwide, which is slightly higher than the Spanish Influenza (H1NI) mortality rate. Compared to acute respiratory syndrome (SARS), this infectious disease (COVID-19) remains an exceptionally transmitted chronic disease globally. ${ }^{31-35}$

In the 21 st century, people with symptoms of higher anxiety levels reported the tendency of excessive social media use. ${ }^{36-40}$ Social media use, such as Facebook, provides platforms, and people can at least tentatively escape their negative emotions. ${ }^{41}$ Here, they can decide which image to create, which site is suitable to visit, and whom to interact with for communication. ${ }^{42}$ The positive experience at media platforms and online experiences lead to developing a close emotional bonding to social media use, which creates a strong desire to stay online permanently. ${ }^{43,44}$ The addictive behavior of social media users indicated a relationship with stress symptoms among young university-level students. ${ }^{36}$ This study explored how health information on social media platforms helps individuals gain correct information about the COVID-19 pandemic. The study focused on examining how excessive social media might increase global mental health risk in the Coronavirus's advent. The study findings should understand the probable link between social media use and emotional trauma individuals facing a public health crisis in response to the OVID-19. This present study offers insights about health information based on the COVID-19 disease available on social media platforms, which have educated people on how to responds to the global health crisis. ${ }^{45}$ The findings' generalizability provides helpful insight and contributes to the scientific literature. The results might offer a stepping-stone to conduct future empirical studies by including other factors to conclude exciting developments.

\section{Literature Review}

The emergence of the COVID-19 pandemic developed a global public health crisis. ${ }^{46}$ People faced many problems and difficulties to resume their normal life functions like before, as the COVID-19 fears, uncertainty, and stress were too much manage virtually. ${ }^{47}$ The COVID-19 health crisis also affected marital life among couples. ${ }^{48-50}$ Women have faced many challenges during the health emergency. ${ }^{51}$ The ongoing pandemic has affected hospital nurses' and health experts' life quality. ${ }^{52}$ Many countries imposed lockdowns and regional social gatherings with the initial signs of the COVID-19 disease, which caused mental stress due to protective measures. However, the suppression measures affected individuals' routine life worldwide. ${ }^{53}$ Uncertainty in a global health crisis leads to Fear and mental health problems due to a heightened sense of threat to life. ${ }^{54}$ An elevated fear in a global health crisis for a long-term period increases the risk of higher mental health concerns. ${ }^{55}$ There is a phenomenal need for further studies to investigate how people coped with the risk of mental health toll ${ }^{56}$ when facing the COVID-19 pandemic. ${ }^{57}$ The WHO dashboard is based on a newsfeed about the COVID-19 virus; there were more than 106.671 million cases and 2.327 million deaths attributed to the fatal infectious disease. As of February 7, 2021, more than 78.361 million infected patients have recovered from the COVID-19 worldwide. ${ }^{58}$

The ongoing COVID-19 transmissible virus resulted in the most deadly global health calamity in this century. ${ }^{59}$ Since World War-II calamity, this COVID-19 outbreak caused massive challenges and crisis management issues, such as economic crisis, social stigma, environmental effects, and health emergency worldwide. ${ }^{60}$ The lethal disease COVID-19 has disrupted social interactions, gatherings, economic activities, transnational relations, and 
global economies. ${ }^{61,62}$ Third-world countries, which make up a large proportion of their population, are labor and low-wage countries. Spatial time analysis for emergency medical requests during the COVID-19 is helpful to enlighten policy and practice to manage the health crisis. $^{63}$ The COVID-19 pandemic has affected them adversely. The complete closure of cities across the country has led to hunger, depression, unemployment, higher anxiety levels, and other psychological disorders. ${ }^{64,65}$ The coronavirus pandemic has affected almost 200 countries, states, and territories worldwide.$^{66}$ From Europe, Italy was the first country that started more buzzing with confirmed patients than Coronavirus and surpassed China's numbers by more than three times. ${ }^{67}$ In the most affected countries, they acknowledged the Coronavirus (2019-nCoV) outbreak out of control. People criticize the government response as a systematic failure to quickly and efficiently exploit and control the epidemic. ${ }^{68}$

\section{Role of Social Media in a Global Health Crisis}

In the advent of the COVID-19 pandemic, people are using social media more than usual routine because they rely on news sources from online sources to seek health information for themselves and their loved ones. ${ }^{69,70}$ Social media platforms' usage has become a welcome relief in the health disaster and global crisis during the ongoing COVID-19 pandemic. $^{71}$ This article holds that analyzing social media usage in the context of global health catastrophes like the COVID-19 pandemic should help disclose the global mental health toll. ${ }^{72}$ The US Census Bureau surveyed more than $42 \%$ of people and identified symptoms of depression and higher anxiety levels in December 2020, which was $11 \%$ higher than the previous year. The survey findings of Hazarika reported similar results of COVID-19 mental stress worldwide. When the global health crisis of COVI19 struck, a telephone service supported by Assam police studied 239 callers in April 2020 and found that $46 \%$ had anxiety, $22 \%$ indicated depression symptoms, and $5 \%$ had suicidal thoughts. It was enough evidence to convince the Government to launch a countrywide remote mental health telephonic service to tackle mental health wellbeing. Physical activities could be medicine for noncommunicable diseases. ${ }^{73}$ After easing lockdowns and restrictions on social distancing in December 2020, the telephonic service collected 43,000 people data and found that $9 \%$ of people had anxiety symptoms, $4 \%$ had depression, and more than $12 \%$ of individuals reported stress related to the health crisis posed by the COVID-19 pandemic. $^{74}$

Indeed, social media platforms have provided easy access to seeking health information, which empowered people to evaluate health-related risks and manage global health concerns. ${ }^{75,76}$ Social media users typically.produce and share health information available through local and international sources in response to a worldwide public health crisis. In the meantime, health professionals and governments have been adopting social media tools to contain and manage health crisis adverse consequences, such as the anthrax attack in various US cities in September 2001, ${ }^{77}$ the 2015 California measles outbreak, ${ }^{78}$ and the 2009 Beijing crisis of H1N1 influenza flu. ${ }^{79}$ The existing literature evidenced that scholars conducted many studies to investigate how the public seeks, creates, and shares health information through the online source in the health emergency crisis. ${ }^{54,78-81}$ Earlier studies in this stream of health crisis mainly centered on users' channel selection. ${ }^{82}$ They identified that people had a greater tendency to rely on traditional media to seeking health information in health crisis events and routine contexts. ${ }^{83}$ In the emergence of health, crisis people use smartphones and social media more than traditional media to seek health information. ${ }^{84}$ In analyzing the mental health problems posed by the COVID-19 pandemic, one of the most significant scientific challenges is to make invisible emotional trauma visible and decipher the vital macro-scale social and technical factors involved. ${ }^{85}$

\section{Social Media, Social Support, and Health Information}

The social media platforms provide the content of social support to the public seeking health information. The people suffering from health anxieties and medical conditions, social media offers them a significant benefit of correct online information. ${ }^{86}$ Social support explains the perception and practicality that how social networks care for and value of people within the networks. It explains how social networks embed individuals into social obligations and communication networks. ${ }^{87}$ The most popular one is how the social network is supportive, and localization of health through sports activities is also helpful. ${ }^{88}$ These supporting resources may include physical and 
emotional care and nourishment, advice, a sense of belonging (companionship), financial assistance (tangible), and personal advice (intangible). Social support refers to the perception and actualization of available aid, help, or the degree to which an individual is integrated into social obligation and network. The sources of social support are coworkers, friends, family members, and organizations. It involves exchanging available resources among people who perceive it as intended to improve the recipient's wellbeing. ${ }^{89}$ Effects of social supportrelated important factors have attracted many clinicians, researchers, scientists, and scholars worldwide. ${ }^{90,91}$ This study inspected the role of social support on mental health and individual well-being. Previous studies indicated that social support is a multidimensional concept based on information, emotion, and peer support to global communities. $^{92}$

\section{Social Media, Health-Related News, and Peer Support}

Social media has played a positive and indispensable role in providing health information from peer support to the public world. ${ }^{93}$ The concept of peer support refers to the informational support provided by others who are helping to share the experiences to provide health information about the health crisis caused by the COVID-19 pandemic. $^{94}$ The most effective and helpful peer support is assistance matching health-related information needs for social media users. ${ }^{95}$ Patients with risk factors need emergency treatment. ${ }^{96}$ The users are eager to seeking information and stay connected with other people, and they share a sense of belonging to the matching group of people. ${ }^{97}$ People receive peer support on social media and other online resources that increase self-efficacy and selfesteem and minimizes the risk of self-uncertainty among people. $^{98}$ Seeking health-related information through social media and social interaction is vital in individuals' lives who need medical treatment due to health problems. $^{99}$ Overall, peer support through social media and online resources complements communication desires to retain social connection and reduce the social isolation necessary to manage mental health disorders, depression, anxiety, and secondary trauma. ${ }^{100,101}$

\section{Social Media Use and Health Behavior}

Social media has provided a platform of updated information for the people who seek health-related information about the COVID-19 pandemic. ${ }^{102}$ People have faced significant pressure and health threat caused by the coronavirus pandemic, which has increased social media use, as people want to seek accurate health-related information and stay connected with peers, friends, and family. ${ }^{103}$ Through social media applications, public communication and interaction go beyond personal massages delivery to seeking correct information and the full scope of the COVID-19 pandemic to develop a real sense of virus prevention. ${ }^{104}$ The emergence of the COVID-19 outbreak has changed life patterns in response to preventive measures. ${ }^{105}$ The ongoing global health crisis has developed a strong sense of coronavirus contagious disease prevention. It might promote health behavior changes, such as maintaining social distancing, using sanitizer, wearing masks, and washing hands. The health behavior theories explain the health behavior model, ${ }^{106}$ which describes why individuals fail to adopt preventive measures or screening tests for the early detection of infectious disease. ${ }^{107}$ The health behavior model helps understand the useful strategies to improve people's health behavior, like adherence to medical treatment against the disease. ${ }^{108}$ The HBM explains that people start to be involved in health-related behavior when people perceive susceptibility to a contagious disease, which has severe health consequences. Its benefits to health-related human behavior outweigh the barriers. ${ }^{109}$

This study's primary purpose is to investigate the indispensable role of social media in the development of COVID19 and to explore how social media can provide reliable information to ordinary people worldwide. The world needs to restore, and the entire country's blockade is no longer a concrete solution because the economy must return to normality as soon as possible. The application of social media technology plays a vital role in responding to the most critical global health crisis. Social media provides upto-date and reliable information to the public. The media platforms assist in adopting virtual learning and teaching models to continue providing education in the interim of the COVID-19 pandemic. Globally, most countries have imposed restrictions on physical interaction and face-toface education at all levels of education to minimize the infection transmission risk of the COVID-19. Educational institutions have turned almost overnight to online teaching, learning, and virtual education to facilitate their student communities. It helps to reduce stress and provide relief to students. The study explores how the COVID-19 pandemic is causing mental health problems around the world. This 


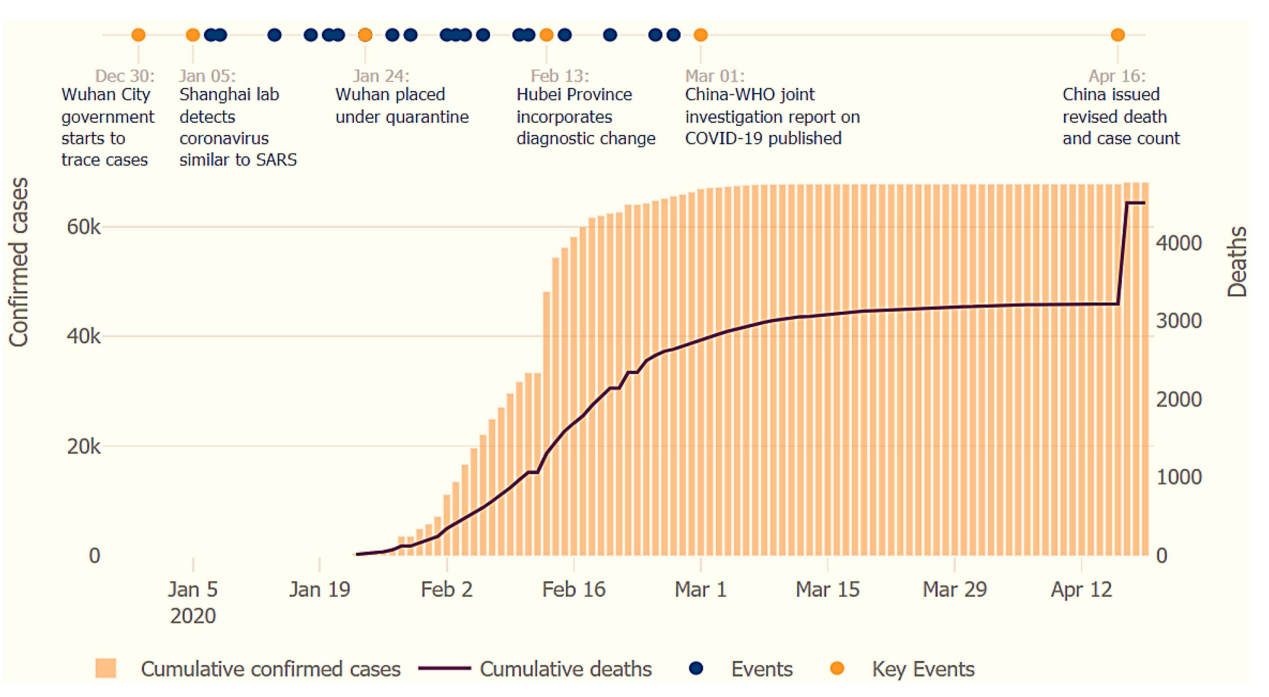

Figure I Timeline of main events of the COVID-19 pandemic in Wuhan city, China. Notes: Data from Abbas et al ${ }^{129}$ and Bao. ${ }^{130}$

study shows Pakistan's background and its global impact in the context of the COVID-19 pandemic. Government officials have chosen smart lock-in, suppression, and mitigation strategies to reduce mental health problems in the existing environment of global health emergencies.

\section{Materials and Methods}

The study incorporated the narrative review analysis based on the existing literature related to mental health problems using the non-pharmaceutical interventions (NPIs) approach to minimize the COVID-19 adverse consequences on global mental health. The study performed a search of the electronic databases available at PsycINFO, PubMed, and LISTA. The survey used search terms, "SARS-CoV-2", "severe acute respiratory syndrome coronavirus-2", COVID-19, "nCoV," "novel coronavirus." Similarly, the search carried about keywords "global mental health," "psychology," "depression," "anxiety," "stress," "social media news related to COVID-19", "infodemic." This study retrieved a total of 110 article citations in the search process. On reviewing the sources, the investigators excluded 42 articles because they dealt with other aspects of the COVID-19 pandemic, such as therapy, drugs, animal models, and organization of the healthcare systems. The review also used the statistical data set reported by the WHO, John Hopkin University, and public hospital/healthcare systems affiliated with the ministry of health, the Government of Pakistan, to draw the results for this article. The statistical data sets about the ongoing coronavirus (2019-nCoV) pandemic are available through Pakistan's health ministry. This current research has drawn results through this data set-ages of the recruited verified patients of the challenging coronavirus disease range from 10 to 86 years.

\section{Results}

The results of this current research stipulated that the combined series of protective measures and intervention strategies are the only useful ways in controlling, managing, and reducing the rapid spread of infectious disease (COVID-19). See Figure 1 below.

Figure 1 specifies the timeline of the critical events of the COVID-19 outbreak in Wuhan city, China. Wuhan Government started tracing COVID-19 infected people on December 30, 2020. Later, the Shanghai Lab detected the COVID-19 virus similar to SARS on January 5, 2020. Wuhan Government placed patients of the Coronavirus under quarantine on January 30, 2020. As of February 13, 2020, Hubei province incorporated diagnostic change to identify the infected people. The china-WHO joint investigation released a report on March 1, 2020, about the outbreak of the COVID-19. The Chinese Government issued revised death and case count on April 16, 2020.

Table 1 shows that Spain reported 200,210 confirmed patients of COVID-19, a case-fatality rate of $10.40 \%$, and a death toll of 20,852. France reported 156,480 confirmed cases, a death toll of 20,292, and a case fatality rate of $13.00 \%$. Similarly, the United Kingdom declared 125,856 cases, total deaths 16,550 with a case-fatality rate of 13.10\%, as of April 21, 2020. 
Table I COVID-19 Cases and Mortality, The Most Affected Countries, as of April 21, 2020 (First Wave)

\begin{tabular}{|l|c|c|c|c|}
\hline Country & Confirmed & Deaths & Case-Fatality & $\begin{array}{c}\text { Deaths/ } \\
\text { I00k Pop. }\end{array}$ \\
\hline US & 784,326 & 42,094 & $5.40 \%$ & 12.87 \\
\hline Italy & 181,228 & 24,114 & $13.30 \%$ & 39.9 \\
\hline Spain & 200,210 & 20,852 & $10.40 \%$ & 44.63 \\
\hline France & 156,480 & 20,292 & $13.00 \%$ & 30.29 \\
\hline United Kingdom & 125,856 & 16,550 & $13.10 \%$ & 24.89 \\
\hline Belgium & 39,983 & 5828 & $14.60 \%$ & 51.02 \\
\hline Iran & 83,505 & 5209 & $6.20 \%$ & 6.37 \\
\hline Germany & 147,065 & 4862 & $3.30 \%$ & 5.86 \\
\hline China & 83,817 & 4636 & $5.50 \%$ & 0.33 \\
\hline Netherlands & 33,588 & 3764 & $11.20 \%$ & 21.84 \\
\hline Brazil & 40,743 & 2587 & $6.30 \%$ & 1.24 \\
\hline Turkey & 90,980 & 2140 & $2.40 \%$ & 2.6 \\
\hline Canada & 37,657 & 1725 & $4.60 \%$ & 4.65 \\
\hline Sweden & 14,777 & 1580 & $10.70 \%$ & 15.52 \\
\hline Switzerland & 27,944 & 1429 & $5.10 \%$ & 16.78 \\
\hline Portugal & 20,863 & 735 & $3.50 \%$ & 7.15 \\
\hline Ireland & 15,652 & 687 & $4.40 \%$ & 14.15 \\
\hline Note:Dar & $150 \%$ \\
\hline
\end{tabular}

Note:Data from CSSE COVID-19 data; unpublished data; February 23, 2021.

\section{Global Situation of the COVID-19}

Transmission - First Wave of the

\section{Pandemic}

Table 1 shows the COVID-19 cases and mortality by the most affected country, as of April 21, 2020, worldwide. According to the WHO's statistics, the USA is still the most affected country with confirmed cases of 784,326, deaths 42,094 , and a case-fatality rate of $5.40 \%$. Italy remained the second most victim of the lethal disease of the COVID-19 and reported 181,228 cases with deaths total of 24,114 and a case fatality rate of $13.30 \%$, as of April 21, 2020.

\section{Global Health Crisis Due to Transmission of the COVID-I9 Pandemic - Second Wave}

By analyzing the current economic problem, it is critical to understand that there was no availability of approved clinical antiviral drugs or useful vaccines to treat the patients of the COVID-19 as of October 2020. A contagious disease spreads from person to person through their droplets present in the air or by touching infected surfaces. The COVID-19 outbreak infected over 36.8 million individuals causing deaths of over 1.067; however, more than 27.697 million people recovered from the transmittable disease as of October 9, 2020, around the world. The second wave of the ongoing COVID-19 pandemic quickly spread to the world, and there were 109.744 million cases, 2.421 million deaths with a global case fatality rate of $2.2 \%$, as of February 15, 2021. There were more than 84.307 million successful recoveries from the ongoing infectious disease. The emergence of the coronavirus epidemic (COVID-19) also disrupted the economy of Pakistan massively. Health officials reported 317,595 virus patients as of October 9, 2020, which has posed substantial social, economic, health crisis, and environmental challenges. ${ }^{110}$ See Figure 2 for the COVID-19 cumulative claims of virus infection.

Figure 2 specifies that there were more than 33.43 million confirmed cases in Europe, 32.38 million cases in North America, 24.48 million cases in Asia, excluding China. There were 17.46 million cases in South America, 3.84 million in Africa, and 32,439 confirmed cases in Oceania. China declared 100,784 confirmed cases of the COVID-19 as of February 23, 2021. Overall, Figure 2 indicated the global view of the COVID19 infection, and there were more than 111.72 million confirmed cases of the COVID-19 worldwide. See Table 2 about cases and mortality.

See Figure 3 for the COVID-19 Case Fatality Rate (CFR) of the COVID-19 worldwide.

Case Fatality Rate (CFR) of the COVID-19 of the most affected countries as indicated by Figure 3 . The casefatality rate was $4.8 \%$ in China, $3.4 \%$ in Italy, $3.1 \%$ in Australia, and $2.9 \%$ in the UK. Similarly, Germany declared a case-fatality rate of $2.8 \%$, Africa, $2.6 \%$, South America, 2.6\%, and Brazil, 2.4\%, respectively. See Figure 4 below on daily new cases/million population.

Figure 4 shows daily new COVID-19 confirmed cases per million people in the selected countries, as of February 23, 2021, worldwide. Figure 4 shows the daily cases in the rolling average of 7-days from February 22, 2020, to February 22, 2021. The number of positive cases of the COVID-19 infection is lower than real case 


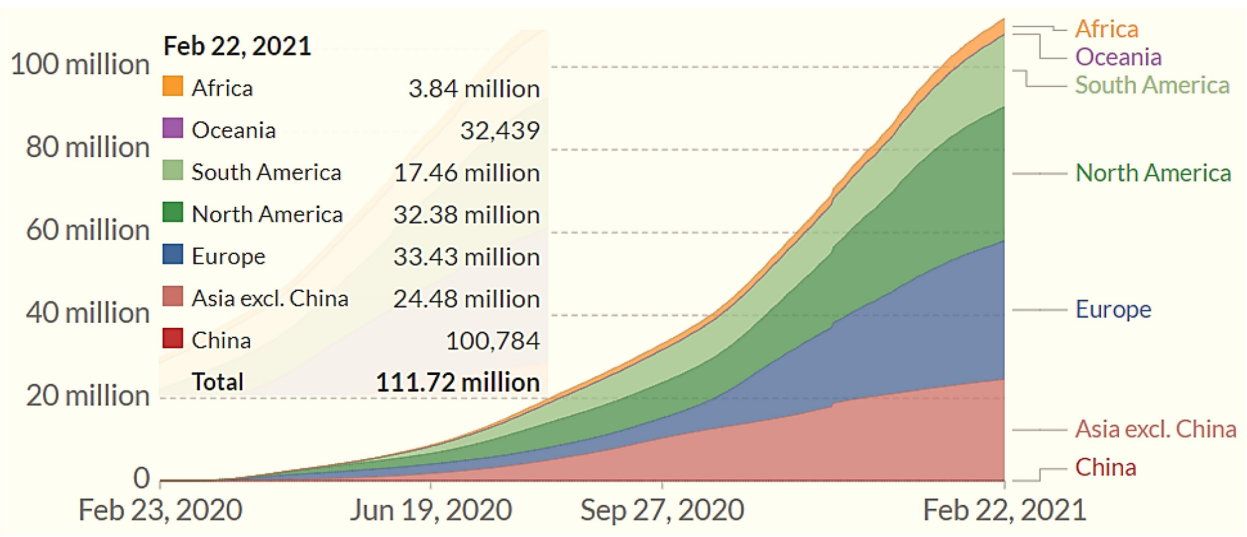

Figure 2 Cumulative confirmed cases of the COVID-19 pandemic, as of February 23, 2021.

Note: Data from CSSE COVID-19 data; unpublished data; February 23, 2021.

numbers, and the foremost reason for that is the limitation in a testing capacity.

\section{The Effects of COVID-19 Pandemic in Pakistan}

The statistics show that on February 26, 2020, a student returned to Karachi from Iran, and the Ministry of Health confirmed the first confirmed patient diagnosed with Coronavirus in Karachi. By March 18, 2020, the registered cases had arrived in Islamabad, four provinces, and two autonomous regions. The data quantified the arrival of a new influenza pandemic (2019-nCoV) through global travelers entering Pakistan. These international tourists are carriers of this transmittable disease. They have traveled to many countries, including Iran, China, Saudi Arabia, the United States, the United Kingdom, Iraq, and European countries. Until March 26, 2020, the Ministry of Health reported verified 1235 cases of infectious disease. As of April 26, 2020, the health ministry declared 13,328 confirmed cases across the country. At present, as of May 28, there are over 300,955 positive or infected cases, and the COVID-19's spread resulted in almost 65,000 confirmed cases in the next 14 days by May 29, 2020 , which shows a very high transmission of the disease. Total deaths were 1317 with a mortality rate of $2.10 \%$, and full recoveries are 22,305 (34.80\%), indicating that the disease's transmission rate is very high. The local transmission and rapid spread extremely infected the Pakistani individuals, and it has developed a challenging situation. The statistics reported ten deaths of doctors and paramedical workers. The COVID-19 pandemic resulted in a massive crisis for the travel and tourism industries. ${ }^{111-113}$ The outbreak of the pandemic has massively affected firm performance. ${ }^{114}$

In Punjab province, 651 people interacted with doctors and paramedical workers, and the health professionals caused the infection to 35 people as of May 14, 020, in Pakistan. As of August 26, 2020, the novel coronavirus (2019-nCoV) pandemic continues to spread rapidly globally, with more than 23.9 million verified patients in more than 188 countries and regions. ${ }^{115}$ More than 15.51 million people have recovered worldwide, and nearly 819,500 have been infected and lost their lives. ${ }^{60}$ The pandemic's peak witnessed confirm 6825 cases in a single day on June 15; however, the trend stabilized with a significant decrease in new patients in Pakistan. ${ }^{116}$ Pakistan reported a 95.3\% recovery rate with 317,595 confirmed cases, with a fatality rate of $2.12 \%$, deaths 6552 , significantly lower than the global average of $3.6 \%$, as of October 2020. During the second wave of the COVID-19, there were 546,428 confirmed cases of the COVID-19 disease, with a recovery rate of $91.7 \%$ (501,252 patients), and the recorded death toll was 11,683 (2.1\%), As of January 31, 2021. There were 572,334 cases, deaths 12,617 with case-fatality rate $2.2 \%$, total recoveries were 535,491 (93.6\%), as of February 23, 2021. ${ }^{62}$

\section{Raiwind Hotspot Super Spreader of the COVID-19}

The Tableeghi Jamaat religious congregation has appeared in Raiwind Markaz during the early days of March 2020. The super-spreader audience with more than 540 verified cases of the infectious disease linked to the religious event and participants came here from across Pakistan. ${ }^{68}$ The Minister of 
Table 2 Cases and Mortality by Most Affected Countries, as of February 23, 2021 (Second-Wave)

\begin{tabular}{|c|c|c|c|c|}
\hline Country & Confirmed & Deaths & Case-Fatality & $\begin{array}{c}\text { Deaths/I 00k } \\
\text { Pop. }\end{array}$ \\
\hline United States & $28,|88,57|$ & 500,244 & $1.8 \%$ & 152.90 \\
\hline India & $11,016,434$ & 156,463 & $1.4 \%$ & 11.57 \\
\hline Brazil & $10,195,160$ & 247,143 & $2.4 \%$ & 117.99 \\
\hline United Kingdom & $4,138,233$ & 120,988 & $2.9 \%$ & 181.97 \\
\hline Russia & $4,130,447$ & 82,255 & $2.0 \%$ & 56.93 \\
\hline France & $3,669,354$ & 84,764 & $2.3 \%$ & 126.54 \\
\hline Spain & $3,|53,97|$ & 67,636 & $2.1 \%$ & 144.76 \\
\hline Italy & $2,8 \mid 8,863$ & 95,992 & $3.4 \%$ & 158.84 \\
\hline Turkey & $2,646,526$ & 28,138 & $1.1 \%$ & 34.18 \\
\hline Germany & $2,399,499$ & 68,363 & $2.8 \%$ & 82.44 \\
\hline Colombia & $2,229,663$ & 58,974 & $2.6 \%$ & 118.78 \\
\hline Argentina & $2,069,751$ & 51,359 & $2.5 \%$ & 115.43 \\
\hline Mexico & $2,043,632$ & 180,536 & $8.8 \%$ & 143.07 \\
\hline Poland & $1,642,658$ & 42,188 & $2.6 \%$ & 111.08 \\
\hline Iran & I,582,275 & 59,572 & $3.8 \%$ & 72.83 \\
\hline South Africa & I,504,588 & 49,150 & $3.3 \%$ & 85.06 \\
\hline Ukraine & I,354,545 & 26,531 & $2.0 \%$ & 59.46 \\
\hline Indonesia & $1,288,833$ & 34,691 & $2.7 \%$ & 12.96 \\
\hline Peru & $1,283,309$ & 45,097 & $3.5 \%$ & 140.98 \\
\hline Czechia & $\mathrm{I}, 157,180$ & 19,330 & $1.7 \%$ & 181.92 \\
\hline Netherlands & $\mathrm{I}, 075,425$ & 15,372 & $1.4 \%$ & 89.21 \\
\hline Pakistan & 573,384 & 12,658 & $2.2 \%$ & 5.96 \\
\hline
\end{tabular}

Note: Data from CSSE COVID-19 data; unpublished data; February 23, 2021.

Science and Technology blamed that clergy inflexibility was not helpful to the national cause. They held the event despite the ongoing worsening coronavirus outbreak. The Punjab Government officials reported that almost 100,000 religious people attended the congregation at the Markaz of Tableeghi Jamaat on March 10, and the majority came from various regions of Pakistan. More than 3000 religious members participated in this event from different 40 foreign countries, and 250,000 attendees participated in this congregation. The government officials have quarantine over 20,000 Tableeghi Jamaat attendees as of April 8, 2020, and Government. ${ }^{117}$ Figure 5 indicates the overall data.
Figure 5 indicates that there are 300,955 infected patients in Pakistan as of September 12, 2020. Sindh is a highly contaminated province with 131,675 cases, followed by Punjab with 97,602, Khyber Pakhtunkhwa (KPK) 36.862, Balochistan 13,401, Gilgit-Baltistan 2164, and Azad Jammu and Kashmir 2389 patients, correspondingly. There are total deaths of 6373 , with $2.1 \%$ of the mortality rate, and real recovered cases are 288,536 (95.90\%), as of September 12, 2020. The Government initiated tracking down the remaining attendees of the religious event. The Government also quarantine all the Zaireen who entered Pakistan after visits to Iran, Iraq, Syria, Saudi Arabia, and many other countries. 
Case-fatality rate (CFR) of the COVID-19

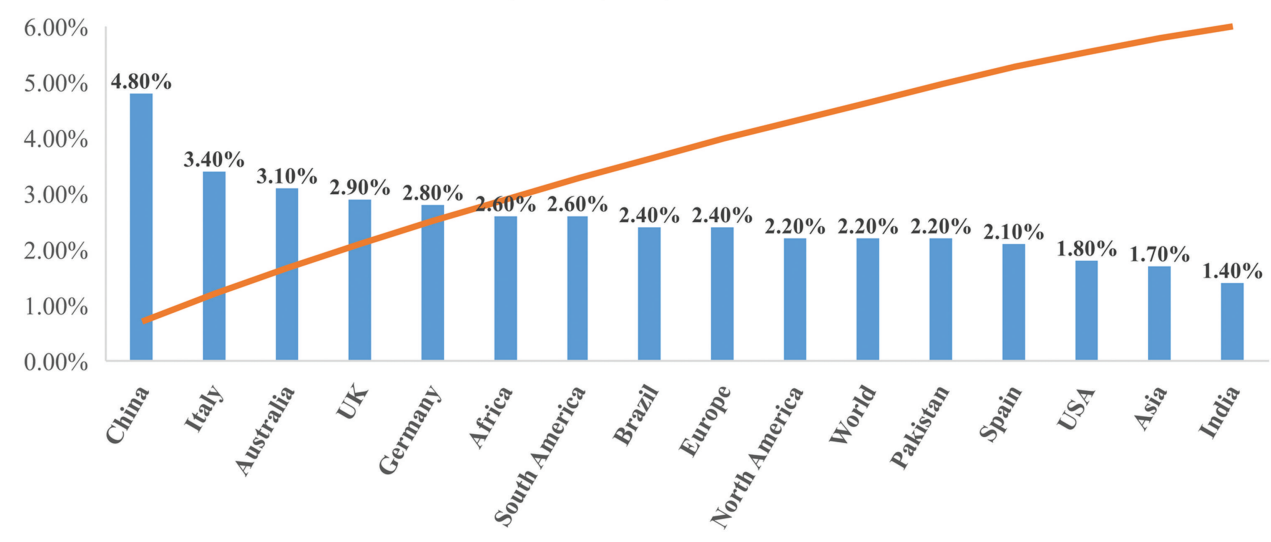

Figure 3 The case fatality rate (CFR) of the COVID-19, as of February 23, 2021, worldwide.

Note: Data from CSSE COVID-19 data; unpublished data; February 23, 2021.

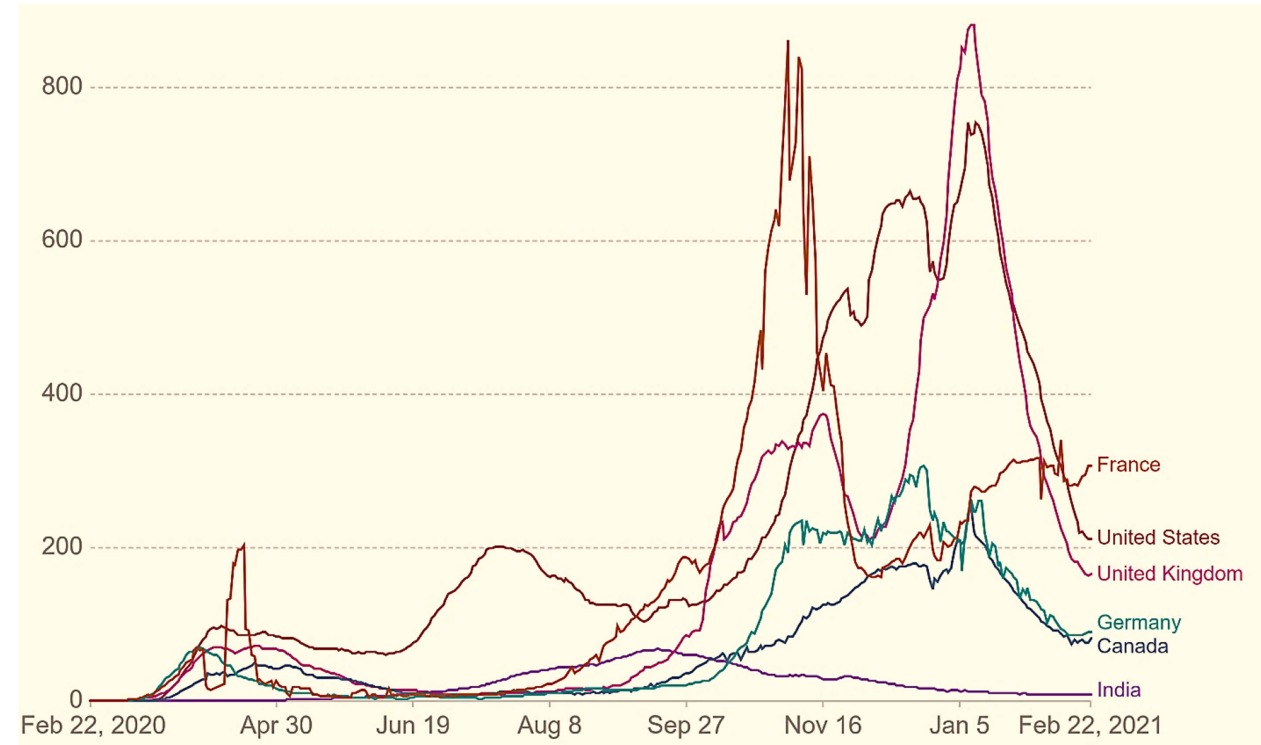

Figure 4 Daily new COVID-19 cases per million population, as of February 23, 2021, worldwide. Note: Data from CSSE COVID-19 data; unpublished data; February 23, 2021.

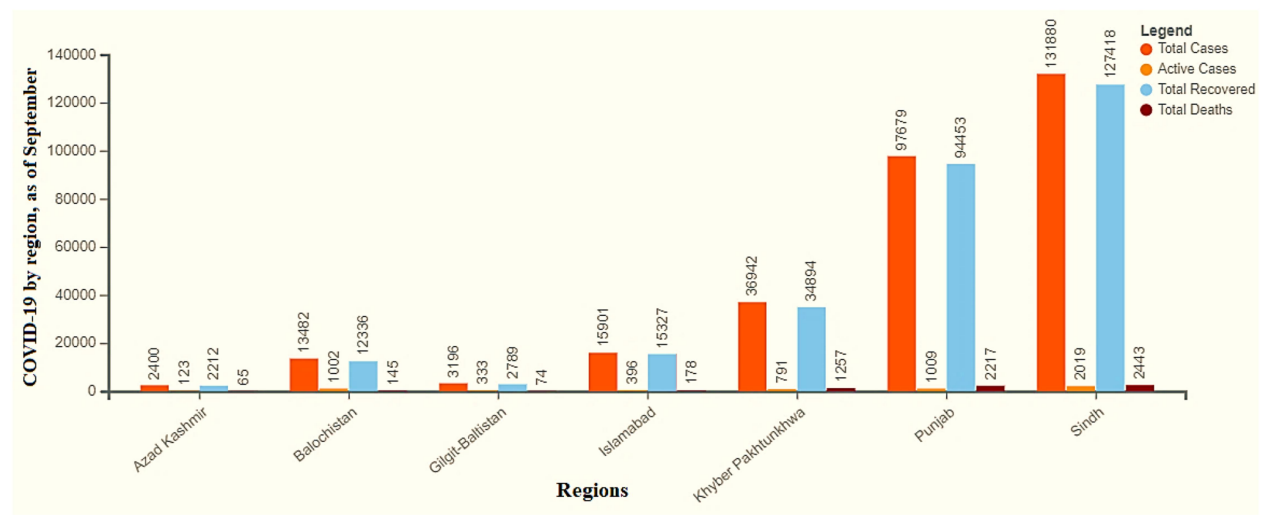

Figure 5 COVID-19 active cases, recovery vs death rate in Pakistan, as of September 12, 2020.

Note: Data from Abbas ${ }^{62}$ and Jafri et al. ${ }^{131}$ 
As of April 20, more than $70 \%$ of transmission of the coronavirus cases indicated the linkage to the people who attended Raiwind religious events and the pilgrims returning from the Middle Eastern countries. ${ }^{118}$ The government data showed that Raiwind religious event over 2000 infected people, which was $27 \%$ of Pakistan's total cases, as of late April 2020.

Still, the figure abruptly increased to 9200 verified cases in the next three weeks (until April 7, 2020), which stipulated a 173.59 times increase in the confirmed patients' total claims. Within the next three weeks, the infection transmission kept growing, and it added 16,473 COVID-19 cases across the country, which indicated a $179.05 \%$ increase in the patients. During the coming ten days, the number of verified patients' of (2019-nCoV) Coronavirus has crossed 31,941 , which specified a double increase of more than $182.10 \%$ all over Pakistan. There are more than 28.5 million infected patients, 19.2 million recoveries, and 917,000 deaths as of September 12, 2020, worldwide. The situation was worst and established severe pressure on healthcare systems management to treat infected patients. The people have not listened to the Government, kept moving around, and ignored the authorities' suppression policy, which caused a sharp spread through local transmission. ${ }^{119}$ There were 573,384 cases, a death toll of $12,658(2.2 \%$ mortality rate), and total recoveries of 536,243 , as of February 23, 2021, in Pakistan.

\section{Discussion}

Public health crises, epidemics, and pandemics always bring stern stress, anxiety symptoms, and worries to global communities, especially those who face virus attacks. The outbreak of the COVID-19 has brought a new series of fears and anxieties about the absence of an effective vaccine, medication, volunteer shortage, practicing social distancing, lack of education on preventive measures, wearing a mask, washing hands, escalating economic woes and individuals concerns about loved one's wellbeing. The appearance of the COVID-19 has increased domestic violence issues and brought the same fears, mental stress, and anxieties worldwide. ${ }^{120}$ Wuhan city was the first identified epicenter of this global health crisis. Consequently, the COVID-19 pandemic posed a challenge to identify specific invisible harm of the virus, including toll on mental health, such as stress, anxieties, depression, and secondary trauma. A previous study uncovered hidden damage like depression, anxiety symptoms, and secondary trauma among Wuhan residents after the COCID-19 struck and the health crisis, and $19.2 \%$ of people showed moderate to severe depression symptoms, and $20.3 \%$ individuals reported moderate to severe symptoms of secondary trauma. The COVID-19 appearance has proved a nervewracking time for people worldwide, and the excessive usage of social media indicated a relationship with health behavior change. People used social media to seeking information about the COVID-19 pandemic. It resulted in health behavior change and helped mitigate and manage the virus threats in the absence of a vaccine, screening, or testing kits.

The emergence of the ongoing pandemic COVID-19 has caused a global health emergency. Despite the relatively higher number of coronavirus cases, the case fatality rate of the COVID-19 stands at $2.2 \%$ in Pakistan, which is slightly higher across Asia at $1.94 \%$. However, the fatality rate is expressively lower than the worldwide average rate at almost 3.3\%. While Pakistan reported the 17th highest confirmed cases count and the world's 23-highest death numbers. The Government imposed a nation-wide lockdown from April 1, extended it twice until May 9, 2020, and eased lockdown in different phases. Pakistan introduced the strategy of smart lockdowns, which imposed lockdown to highly infected areas. This policy received appreciation worldwide. The distribution of the COVID19 cases heavily originated from a few central regions in Pakistan. Karachi is the most extensive city recorded cases, making up $28.1 \%$ of infected patients in Pakistan. Lahore stood at the second-largest town and reported confirmed patients, making up almost $16 \%$ of the country's cases. Peshawar district and Islamabad Capital Territory (ICT), Islamabad, Peshawar, Lahore, and Karachi made up nearly $55 \%$ of Pakistan's total cases.

\section{Role of Social Media and Technological Tools for Educating Provision}

Information technology has significantly affected multiple aspects of human lives in recent times; however, technology has played an indispensable role in education provision at levels, including primary, secondary, and higher education worldwide. The use of educational technology has gained popularity increasingly in the education industry. ${ }^{121}$ There was tremendous global growth in education provision at all levels during the last few decades. However, the spread of the COVID-19 has developed a big challenge for national education systems in providing education. ${ }^{122}$ Governments in numerous countries have 
ordered educational institutions to suspend face-to-face academic learning, instruction for their students until the global situation gets better and the coronavirus spread comes under control. This emergency compelled universities and educational institutes to switch their education mode overnight, and educational institutes adopted online teaching and virtual learning through technology usage. ${ }^{123}$ However, learning and teaching mode by using virtual technology is not a new phenomenon for education provision. During the last decades, several educational institutes have incorporated the face-to-face method of teaching. ${ }^{124}$ In the COVID-19 health crisis, other assessment options help use online training through educational technology have to consider problems in unique educational settings to tackle the health emergency. ${ }^{125}$ Educational institutions adopted the required online education provision features and continued delivering online teaching and learning. ${ }^{126}$

The global and Pakistan media platforms have played an indispensable role in mitigating mental health's psychological effects. Different media channels launched special transmissions and invited health professionals to provide useful information on the pandemic COVID-19. Experts discussed the preventive measures to combat the outbreak of the novel virus. The media in Pakistan enjoys broadcasting freedom, and it influences the public's daily life. ${ }^{127}$ The media played a positive and responsible role in the critical situation of the COVID-19 outbreak for the people's wellbeing and provided updated information. Media hosts invited healthcare experts, psychiatrists, and psychologists in dedicated programs and experts to instruct and advise how to cope with this stressful situation to avoid mental strain without distressing their mental health. The special reliable programs on the COVID-19 campaigns boosted the public's morale and provided them mental relief. $^{128}$

\section{Conclusion}

This research identifies that the excessive usage of social media content in the appearance of a global health crisis might be rewarding and useful to obtain emotional, informational, and peer support; however, at the same time, it increases the toll on mental health. There is no easy fixed way to distress disorders when a pandemic or an epidemic attacks human beings. Coping with the ordinary methods can help deal with new stressors, while some people might try to reinforce an austere sense of resilience. The study findings imply taking a break from social media use from time-to-time, which helps improve mental wellbeing in the advent of the COVID-19 pandemic.
Since the prevalence of the deadly virus, COVID-19 spreads pear to people at the social level. It is necessary to take appropriate mental and physical health prevention measures, especially in less developed countries such as Pakistan. These countries have minimal resources, and healthcare systems' management is not sufficiently developed or advanced in detecting disease outbreaks promptly. There is a high demand to resolve the mental health toll. Psychiatrists, health specialists, Psychologists, and paramedical staff can help in treating patients. They can aid in avoiding and mitigating the long-term spread of the infectious (2019-nCoV) virus. Numerous strategies, such as an online psychological helpline, can also work by staying at home. It facilitates citizens to seek mental health advice from psychologists and other health professionals and can easily maintain communication and obtain the assistance they need. The respondents' critical elements suggest that extensive testing of suspects is required on a large scale, tracking active transmitters and a rigorous focus on home diagnosis.

The public needs care and protection from the virus, and medical experts and paramedical personnel can take care to manage the toll on mental health. Health experts are fighting from the front against this deadly disease worldwide. Social media provided platforms to seek health information for those who desired health-related information in the outbreak of the COVID-19. Globally, individuals faced massive pressure and the health threat posed by the ongoing pandemic the COVID-19 that increased social media use. The public needed correct health-related information and stayed connected with coworkers, peers, friends, and family members. Masses involved in using social media and other technological tools to seeking significant emotional, informational, and peer support to obtain health-related information. More social media use leads to a more substantial level of healthrelated information accessible to the people. They started wearing facemasks, washing hands and practicing social distancing, which predicted emotional, informational, and peers support.

\section{Implications}

This study provides practical implications to develop effective strategies in managing toll to mental health in the appearance of the global health crisis. This study bids evidence-based insights to the health professional to provide healthcare and psychological services to patients in need of medication or treatment. With the underlying nature of mental health toll and the burden on healthcare systems, it is evident that the health crisis leads to mental 
disorders in the community when the infected people overwhelm the hospitals and other medical units in the pandemic COVID-19. Epidemics and pandemics viruses have always been a fatal foe of human beings. The human immune system evolves to protect the physical health in most infectious viruses' attacks; however, it cannot control psychological damages. The health experts and officials need to pay more and dedicated attention to the health crisis to make health policy that could help advise the public of taking a medical break in the advent of the COVID-19 pandemic. Implications of the existing evidence documented that the appearance of the COVID-19 pandemic posed a toll on mental health and developed mental disorders worldwide.

This study's underpinning implications indicate a direct relationship between the pandemic COVID-19 and mental health. The consequences of the COVID-19 pandemic and various mental disorders have deep roots in the general public and health professionals. Still, it has also affected global human societies on a larger scale, and it has developed a global health crisis. This study highlighted the indispensable role of social media in seeking health-related information and social support through social media usage. The study argues that mental health issues are critical factors in everyday public health. The implications of this research specified that a series of protective measures, such as wearing masks, social distancing, washing hands, and other interventional strategies to control, manage, and reduce the spread of contagious disease. The results also specified that health specialists might not ignore any single intervention measure to combat the COVID-19 pandemic.

\section{Limitations}

This research has indicated some limitations, like other research studies. This research has not detracted, but the broader importance of implementing protective measures, monitoring, and preventive strategies are useful in reducing contagious disease. The other limitations include that the research has not followed experimental or clinical settings. Additional studies can use empirical data with the cross-sectional design and clinical settings to add various influencing factors to explore mental health impacts. This study's findings contribute to a broader discourse focusing on individuals' mental health issues and psychological disorders. The COVID-19 has led to psychological problems among people under the prevailing health crisis. The scholars recommend that other influencing factors need more explanation, which might contribute to public mental health caused by a coronavirus. In the future, longitudinal and further cross-sectional studies would uncover causal relationships based on various factors to find the effects on mental health during the COVID-19 pandemic. The current research has not developed or proposed likely new intervention strategies and health policies that minimize the mental health toll in the appearance of the COVID-19 health crisis and beyond. Further researches might help to work out and identifying some useful coping methods for mental health susceptibility and health behavior change. The discussed insights are vital and helpful to build a robust health ecosystem in the emergence of a pandemic and global public health crisis.

\section{Abbreviations}

TB, Tuberculosis; UK, The United Kingdom; KPK, Khyber Pakhtunkhwa; NIH, National Institute of Health; USA, The United States of America; 2019-nCoV, 2019 novel coronavirus; OCD, Obsessive-compulsive disorder; HIV, Human immunodeficiency virus; COVID-19, Coronavirus disease 2019; WHO, The World Health Organization; SARS, Severe acute respiratory syndrome; MERS, The Middle East respiratory syndrome; SARS-CoV-2, Severe acute respiratory syndrome coronavirus 2; H1N1, Influenza A virus subtype (A/H1N1), the subtype of Influenza A virus.

\section{Data Sharing Statement}

Data is available at the request of the corresponding author.

\section{Acknowledgment}

Authors are thankful for professional EDITAGE editing language services to ensure that English grammar is free of errors in this manuscript.

\section{Author Contributions}

All authors contributed to data analysis, drafting or revising the article, have agreed on the journal to which the article will be submitted, gave final approval of the version to be published, and agree to be accountable for all aspects of the work.

\section{Funding}

This research was sponsored and funded by National Social Science Fund of China (20BXW042).

\section{Disclosure}

The authors report no conflicts of interest for this work. 


\section{References}

1. Munnoli PM, Nabapure S, Yeshavanth G. Post-COVID-19 precautions based on lessons learned from past pandemics: a review. Z Gesundh Wiss. 2020;1-9.

2. Shuja $\mathrm{KH}$, Aqeel $\mathrm{M}$, Khan EA, et al. Letter to highlight the effects of isolation on elderly during COVID-19 outbreak. Int J Geriatr Psychiatry. 2020;35(12):1477-1478. doi:10.1002/ gps. 5423

3. Shorey S, Chan V. Lessons from past epidemics and pandemics and a way forward for pregnant women, midwives and nurses during COVID-19 and beyond: a meta-synthesis. Midwifery. 2020;90:102821. doi:10.1016/j.midw.2020.102821

4. Matterne U, Egger N, Tempes J, et al. Health literacy in the general population in the context of epidemic or pandemic coronavirus outbreak situations: rapid scoping review. Patient Educ Couns. 2021;104(2):223-234. doi:10.1016/j.pec.2020.10.012

5. Hakes NA, Choi J, Spain DA, et al. Lessons from epidemics, pandemics, and surgery. $J$ Am Coll Surg. 2020;231(6):770-776. doi:10.1016/j.jamcollsurg.2020.08.736

6. Scheidel W. The Great Leveler: Violence and the History of Inequality from the Stone Age to the Twenty-First Century. Princeton University Press; 2018.

7. Hays JN. Epidemics and Pandemics: Their Impacts on Human History. ABC-CLIO; 2005.

8. Brown E, Gray R, Lo Monaco S, et al. The potential impact of COVID-19 on psychosis: a rapid review of contemporary epidemic and pandemic research. Schizophr Res. 2020;222:79-87. doi:10.1016/j.schres.2020.05.005

9. Tsatsakis A, Petrakis D, Nikolouzakis TK, et al. COVID-19, an opportunity to reevaluate the correlation between long-term effects of anthropogenic pollutants on viral epidemic/pandemic events and prevalence. Food Chem Toxicol. 2020;141:111418. doi:10.1016/j.fct.2020.111418

10. Parija SC. Textbook of Microbiology and Immunology, 2/e. Elsevier India; 2012.

11. Etkind SN, Bone AE, Lovell N, et al. The role and response of palliative care and hospice services in epidemics and pandemics: a rapid review to inform practice during the COVID-19 pandemic. J Pain Symptom Manage. 2020;60(1):e31-e40. doi:10.1016/j.jpainsymman.2020.03.029

12. Menadue CB. Pandemics, epidemics, viruses, plagues, and disease: comparative frequency analysis of a cultural pathology reflected in science fiction magazines from 1926 to 2015. Soc Sci Humanit Open. 2020;2(1):100048. doi:10.1016/j.ssaho.2020.100048

13. Linas BP, Savinkina A, Barbosa C, et al. A clash of epidemics: impact of the COVID-19 pandemic response on opioid overdose. $J$ Subst Abuse Treat. 2021;120:108158. doi:10.1016/j.jsat.2020.108158

14. Parhizkar E, Rafieipour P, Sepasian A, et al. Synthesis and cytotoxicity evaluation of gemcitabine-tobacco mosaic virus conjugates. $J$ Drug Deliv Sci Technol. 2021;62:102388. doi:10.1016/j.jddst.2021.102388

15. Van Regenmortel MHV. Tobacco mosaic virus (virgaviridae). In: Bamford DH, Zuckerman M, editors. Encyclopedia of Virology. Oxford: Academic Press; 2021:727-733.

16. Huang CT, Sung C-W, Chen C-H, et al. The impact of previous epidemic disease on mental health in physicians and nurses during COVID-19 pandemic. Am J Emerg Med. 2021. doi:10.1016/j. ajem.2021.01.082

17. Lostroh P. Molecular and Cellular Biology of Viruses. CRC Press; 2019.

18. Munnoli PM, Nabapure S, Yeshavanth G. Post-COVID-19 precautions based on lessons learned from past pandemics: a review. J Public Health (Bangkok). 2020. doi:10.1007/s10389-020-01371-3

19. Paniker CKJ, Ghosh S. Paniker's Textbook of Medical Parasitology. Jaypee Brothers,Medical Publishers Pvt. Limited; 2017.
20. Shuja KH, Aqeel M, Jaffar A, et al. COVID-19 pandemic and impending global mental health implications. Psychiatr Danub. 2020;32(1):32-35. doi:10.24869/psyd.2020.32

21. Segovia-Juarez J, Castagnetto JM, Gonzales GF. High altitude reduces infection rate of COVID-19 but not case-fatality rate. Respir Physiol Neurobiol. 2020;281:103494. doi:10.1016/j.resp.2020.103494

22. Kiani B, Rahmati A, Bergquist R, et al. Comparing spatio-temporal distribution of the most common human parasitic infections in Iran over two periods 2007 to 2012 and 2013 to 2018: a systematic quantitative literature review. Int $J$ Health Plann Manage. 2020;35(5):1023-1040. doi:10.1002/hpm.3010

23. Panovska-Griffiths J. Can mathematical modelling solve the current Covid-19 crisis? BMC Public Health. 2020;20(1):551. doi:10.1186/s12889-020-08671-z

24. Xiong D, Zhang L, Watson GL, et al. Pseudo-likelihood based logistic regression for estimating COVID-19 infection and case fatality rates by gender, race, and age in California. Epidemics. 2020;33:100418. doi:10.1016/j.epidem.2020.100418

25. Gao Z, Xu Y, Sun C, et al. A systematic review of asymptomatic infections with COVID-19. J Microbiol Immunol Infect. 2020.

26. Sahraian MA, Azimi A, Navardi S, et al. Evaluation of the rate of COVID-19 infection, hospitalization and death among Iranian patients with multiple sclerosis. Mult Scler Relat Disord. 2020;46:102472. doi:10.1016/j.msard.2020.102472

27. Baud D, Qi X, Nielsen-Saines K, et al. Real estimates of mortality following COVID-19 infection. Lancet Infect Dis. 2020;20 (7):773. doi:10.1016/S1473-3099(20)30195-X

28. Ahmed SF, Quadeer AA, McKay MR. Preliminary identification of potential vaccine targets for the COVID-19 coronavirus (SARS-CoV-2) based on SARS-CoV immunological studies. Viruses. 2020;12(3):254. doi:10.3390/v12030254

29. Wang Y, Wang Y, Chen Y, et al. Unique epidemiological and clinical features of the emerging 2019 novel coronavirus pneumonia (COVID-19) implicate special control measures. $J$ Med Virol. 2020;92(6):568-576. doi:10.1002/jmv.25748

30. Ippolito G, Lauria FN, Locatelli $F$, et al. Lessons from the COVID-19 pandemic-unique opportunities for unifying, revamping and reshaping epidemic preparedness of europe's public health systems. Int $J$ Infect Dis. 2020;101:361-366. doi:10.1016/ j.ijid.2020.10.094

31. Bouey J. From SARS to 2019-Coronavirus (Ncov): US-China Collaborations on Pandemic Response. 2020.

32. Li W, Yang Y, Liu Z-H, et al. Progression of mental health services during the COVID-19 outbreak in China. Int J Biol Sci. 2020;16(10):1732-1738. doi:10.7150/ijbs. 45120

33. Staguhn ED, Weston-Farber E, Castillo RC. The impact of statewide school closures on COVID-19 infection rates. Am J Infect Control. 2021. doi:10.1016/j.ajic.2021.01.002

34. Brody BD, Shi Z, Shaffer C, et al. COVID-19 infection rates in patients referred for psychiatric admission during a regional surge: the case for universal testing. Psychiatry Res. 2021;298:113833. doi:10.1016/j.psychres.2021.113833

35. Travers JL, Agarwal M, Estrada LV, et al. Assessment of COVID-19 infection and mortality rates among nursing homes with different proportions of black residents. $J$ Am Med Dir Assoc. 2021. doi:10.1016/j.jamda.2021.02.014

36. Apaolaza V, Hartmann P, D'Souza C, et al. Mindfulness, compulsive mobile social media use, and derived stress: the mediating roles of self-esteem and social anxiety. Cyberpsychol Behav Soc Netw. 2019;22(6):388-396. doi:10.1089/cyber.2018.0681

37. Atroszko PA, Balcerowska JM, Bereznowski P, et al. Facebook addiction among Polish undergraduate students: validity of measurement and relationship with personality and well-being. Comput Human Behav. 2018;85:329-338. doi:10.1016/j. chb.2018.04.001 
38. Brailovskaia J, Margraf J. Relationship between depression symptoms, physical activity, and addictive social media use. Cyberpsychol Behav Soc Netw. 2020;23(12):818-822. doi:10.1089/ cyber.2020.0255

39. Primack BA, Shensa A, Escobar-Viera CG, et al. Use of multiple social media platforms and symptoms of depression and anxiety: a nationally-representative study among U.S. young adults. Comput Human Behav. 2017;69:1-9. doi:10.1016/j. chb.2016.11.013

40. Abbas J, Aman J, Nurunnabi M, et al. The impact of social media on earning behavior for sustainable education: evidence of students from selected universities in Pakistan. Sustainability. 2019;11(6):1683. doi:10.3390/su11061683

41. Marino C, Gini G, Vieno A, et al. A comprehensive meta-analysis on problematic facebook use. Comput Human Behav. 2018;83:262-277. doi:10.1016/j.chb.2018.02.009

42. Boyd DM, Ellison NB. Social network sites: definition, history, and scholarship. J Comput Mediat Commun. 2007;13(1):210-230. doi:10.1111/j.1083-6101.2007.00393.x

43. Brailovskaia J, Schillack H, Margraf J. Facebook addiction disorder in Germany. Cyberpsychol Behav Soc Netw. 2018;21 (7):450-456. doi:10.1089/cyber.2018.0140

44. Moradi F, Tourani S, Ziapour A, et al. Emotional intelligence and quality of life in elderly diabetic patients. Int $Q$ Community Health Educ. 2020;272684X20965811.

45. Local Burden of Disease, H.I.V.C. Mapping subnational HIV mortality in six Latin American countries with incomplete vital registration systems. BMC Med. 2021;19(1):4. doi:10.1186/ s12916-020-01876-4

46. Bergquist R, Kiani B, Manda S. First year with COVID-19: assessment and prospects. Geospat Health. 2020;15(2).

47. $\mathrm{Su} \mathrm{Z,} \mathrm{McDonnell} \mathrm{D,} \mathrm{Wen} \mathrm{J,} \mathrm{et} \mathrm{al.} \mathrm{Mental} \mathrm{health} \mathrm{consequences} \mathrm{of}$ COVID-19 media coverage: the need for effective crisis communication practices. Global Health. 2021;17(1):4. doi:10.1186/ s12992-020-00654-4

48. Aman J, Abbas J, Nurunnabi M, et al. The relationship of religiosity and marital satisfaction: the role of religious commitment and practices on marital satisfaction among Pakistani respondents. Behav Sci (Basel). 2019;9(3):30. doi:10.3390/bs9030030

49. Campbell AM. An increasing risk of family violence during the Covid-19 pandemic: strengthening community collaborations to save lives. Forensic Sci Int. 2020;2:100089.

50. Arenas-Arroyo E, Fernandez-Kranz D, Nollenberger N. Intimate partner violence under forced cohabitation and economic stress: evidence from the COVID-19 pandemic. $J$ Public Econ. 2021;194:104350. doi:10.1016/j.jpubeco.2020.104350

51. Yoosefi Lebni J, Abbas J, Khorami F, et al. Challenges facing women survivors of self-immolation in the Kurdish regions of Iran: a Qualitative Study. Front Psychiatry. 2020;11(778):778. doi:10.3389/fpsyt.2020.00778

52. Lebni JY, Toghroli R, Abbas J, et al. Nurses' work-related quality of life and its influencing demographic factors at a public hospital in western Iran: a Cross-Sectional Study. Int Q Community Health Educ. 2020;272684X20972838.

53. The L. COVID-19: fighting panic with information. Lancet. 2020;395(10224):537. doi:10.1016/S0140-6736(20)30379-2

54. Avery EJ. Public information officers' social media monitoring during the Zika virus crisis, a global health threat surrounded by public uncertainty. Public Relat Rev. 2017;43(3):468-476. doi:10.1016/j.pubrev.2017.02.018

55. NeJhaddadgar N, Ziapour A, Zakkipour G. et al. Effectiveness of telephone-based screening and triage during COVID-19 outbreak in the promoted primary healthcare system: a case study in Ardabil province, Iran. Z Gesundh Wiss. 2020;1-6. doi:10.1007/ s10389-020-01407-8
56. Hashtarkhani S, Kiani B, Bergquist R, et al. An age-integrated approach to improve measurement of potential spatial accessibility to emergency medical services for urban areas. Int J Health Plann Manage. 2020;35(3):788-798. doi:10.1002/ hpm. 2960

57. Gandhi RT, Lynch JB, Del Rio C, Solomon CG. Mild or moderate covid-19. N Engl J Med. 2020;383(18):1757-1766. doi:10.1056/ NEJMcp2009249

58. Thorlund K, Dron L, Park J, et al. A real-time dashboard of clinical trials for COVID-19. Lancet Digit Health. 2020;2(6): e286-e287. doi:10.1016/S2589-7500(20)30086-8

59. Dong E, Du H, Gardner L. An interactive web-based dashboard to track COVID-19 in real time. Lancet Infect Dis. 2020;20 (5):533-534. doi:10.1016/S1473-3099(20)30120-1

60. Salamatbakhsh M, Mobaraki K, Sadeghimohammadi S, et al. The global burden of premature mortality due to the Middle East respiratory syndrome (MERS) using standard expected years of life lost, 2012 to 2019. BMC Public Health. 2019;19(1):1523. doi:10.1186/s12889-019-7899-2

61. Turner-Musa J, Ajayi O, Kemp L. Examining Social Determinants of Health, Stigma, and COVID-19 Disparities. Healthcare (Basel). 2020;8(2):168.

62. Abbas J. The impact of coronavirus (SARS-CoV2) epidemic on individuals mental health: the protective measures of Pakistan in managing and sustaining transmissible disease. Psychiatr Danub. 2020;32(3-4):472-477. doi:10.24869/psyd.2020.472

63. Azimi A, Bagheri N, Mostafavi SM, et al. Spatial-time analysis of cardiovascular emergency medical requests: enlightening policy and practice. BMC Public Health. 2021;21(1):7. doi:10.1186/ s12889-020-10064-1

64. Ahmad T, Khan M, Khan FM, et al. Are we ready for the new fatal coronavirus: scenario of Pakistan? Hum Vaccin Immunother. 2020;16(3):736-738. doi:10.1080/21645515.2020.1724000

65. Arshad Ali S, Baloch M, Ahmed N, et al. The outbreak of coronavirus disease 2019 (COVID-19)-an emerging global health threat. J Infect Public Health. 2020;13(4):644-646. doi:10.1016/j. jiph.2020.02.033

66. Sang X, Menhas R, Saqib ZA, et al. The psychological impacts of COVID-19 home confinement and physical activity: a structural equation model analysis. Front Psychol. 2020;11(3910):614770. doi:10.3389/fpsyg.2020.614770

67. Walker PG, Whittaker C, Watson O, et al. The Global Impact of COVID-19 and Strategies for Mitigation and Suppression. Imperial College London; 2020.

68. Paital B, Das K, Parida SK. Inter nation social lockdown versus medical care against COVID-19, a mild environmental insight with special reference to India. Sci Total Environ. 2020;728:138914. doi:10.1016/j.scitotenv.2020.138914

69. de Calheiros Velozo J, Stauder JEA. Exploring social media use as a composite construct to understand its relation to mental health: a pilot study on adolescents. Child Youth Serv Rev. 2018;91:398-402. doi:10.1016/j.childyouth.2018.06.039

70. Li Y, Wang X, Lin X, et al. Seeking and sharing health information on social media: a net valence model and cross-cultural comparison. Technol Forecast Soc Change. 2018;126:28-40. doi:10.1016/j.techfore.2016.07.021

71. Zhong B, Huang Y, Liu Q. Mental health toll from the coronavirus: social media usage reveals Wuhan residents' depression and secondary trauma in the COVID-19 outbreak. Comput Human Behav. 2021;114:106524. doi:10.1016/j. chb.2020.106524

72. Lebni JY, Toghroli R, Abbas J, et al. A study of internet addiction and its effects on mental health: a study based on Iranian University Students. J Educ Health Promot. 2020;25(1):205. doi:10.4103/jehp. jehp_148_20 
73. Saqib ZA, Dai J, Menhas R, et al. Physical activity is a medicine for non-communicable diseases: a survey study regarding the perception of physical activity impact on health wellbeing. Risk Manag Healthc Policy. 2020;13:2949-2962. doi:10.2147/RMHP. S280339

74. Abbott A. COVID's mental-health toll: how scientists are tracking a surge in depression. Nature. 2021;590(7845):194-195. doi:10.1038/d41586-021-00175-z

75. Roundtree AK. Social health content and activity on Facebook. J Tech Writ Commun. 2016;47(3):300-329. doi:10.1177/0047281616641925

76. Tonsaker T, Bartlett G, Trpkov C. Health information on the Internet: gold mine or minefield? Can Fam Physician. 2014;60 (5):407-408

77. Reynolds B, Seeger M. Crisis and emergency risk communication as an integrative model. $J$ Health Commun. 2005;10(1):43-55. doi:10.1080/10810730590904571

78. Meadows CW, Meadows CZ, Tang L, et al. Unraveling public health crises across stages: understanding Twitter emotions and message types during the california measles outbreak. Commun Stud. 2019;70(4):453-469. doi:10.1080/10510974.2019.1582546

79. $\mathrm{Hu} \mathrm{B}$, Zhang D. Channel selection and knowledge acquisition during the 2009 Beijing H1N1 flu crisis: a media system dependency theory perspective. Chin J Commun. 2014;7(3):299-318. doi:10.1080/17544750.2014.926951

80. Park S, Boatwright B, Johnson Avery E. Information channel preference in health crisis: exploring the roles of perceived risk, preparedness, knowledge, and intent to follow directives. Public Relat Rev. 2019;45(5):101794. doi:10.1016/j.pubrev.2019.05.015

81. Bauer A, Garman E, McDaid D, et al. Integrating youth mental health into cash transfer programmes in response to the COVID-19 crisis in low-income and middle-income countries. Lancet Psychiatry. 2021. doi:10.1016/S2215-0366(20)30382-5

82. Halimi L, Bagheri N, Hoseini B, et al. Spatial analysis of colorectal cancer incidence in Hamadan province, Iran: a retrospective cross-sectional study. Appl Spat Anal Policy. 2019;13 (2):293-303. doi:10.1007/s12061-019-09303-9

83. Avery E. Contextual and audience moderators of channel selection and message reception of public health information in routine and crisis situations. J Public Relat Res. 2010;22(4):378-403. doi:10.1080/10627261003801404

84. Goshayeshi L, Pourahmadi A, Ghayour-Mobarhan M, et al. Colorectal cancer risk factors in north-eastern Iran: a retrospective cross-sectional study based on geographical information systems, spatial autocorrelation and regression analysis. Geospat Health. 2019;14(2).

85. Jones CL, Jensen JD, Scherr CL, et al. The health belief model as an explanatory framework in communication research: exploring parallel, serial, and moderated mediation. Health Commun. 2015;30(6):566-576. doi:10.1080/10410236.2013.873363

86. Ouyang A, Inverso NA, Chow S-M, et al. Mo1639 "listening" to IBS patients in the 21st century: offerings from an on-line self help and support group. Gastroenterology. 2016;150(4):S739. doi:10.1016/S0016-5085(16)32510-0

87. Stephens MH, Petrie KJ. Social support and recovery from disease and medical procedures. In: Wright JD, editor. International Encyclopedia of the Social \& Behavioral Sciences. Oxford: Elsevier; 2015:735-740.

88. Dai J, Menhas R. Sustainable development goals, sports and physical activity: the localization of health-related sustainable development goals through sports in China: a narrative review. Risk Manag Healthc Policy. 2020;13:1419-1430. doi:10.2147/ RMHP.S257844

89. Tengku Mohd TAM, Yunus RM, Hairi F, et al. Social support and depression among community dwelling older adults in Asia: a systematic review. BMJ Open. 2019;9(7):e026667. doi:10.1136/bmjopen-2018-026667
90. Abbas J, Aqeel M, Abbas J, et al. The moderating role of social support for marital adjustment, depression, anxiety, and stress: evidence from Pakistani working and nonworking women. $J$ Affect Disord. 2019;244:231-238. doi:10.1016/j.jad.2018.07.071

91. Antonucci TC. Social support, psychology of. In: Smelser NJ, Baltes PB, editors. International Encyclopedia of the Social \& Behavioral Sciences. Pergamon: Oxford; 2001:14465-14469.

92. Yang F, Zhong B, Kumar A, et al. Exchanging social support online: a longitudinal social network analysis of irritable bowel syndrome patients' interactions on a health forum. Journal Mass Commun $Q$. 2017;95(4):1033-1057. doi:10.1177/ 1077699017729815

93. Fang J, Wang X, Wen Z, et al. Fear of missing out and problematic social media use as mediators between emotional support from social media and phubbing behavior. Addict Behav. 2020;107:106430. doi:10.1016/j.addbeh.2020.106430

94. Tan YT, Rehm IC, Stevenson JL, et al. Social media peer support groups for obsessive-compulsive and related disorders: understanding the predictors of negative experiences. J Affect Disord. 2021;281:661-672. doi:10.1016/j.jad.2020.11.094

95. Hosseini N, Fakhar F, Kiani B, et al. Enhancing the security of patients' portals and websites by detecting malicious web crawlers using machine learning techniques. Int $J$ Med Inform. 2019;132:103976. doi:10.1016/j.ijmedinf.2019.103976

96. Firouraghi N, Bagheri N, Kiani F, et al. A spatial database of colorectal cancer patients and potential nutritional risk factors in an urban area in the Middle East. BMC Res Notes. 2020;13 (1):466.

97. Brewer MB. The social self: on being the same and different at the same time. Pers Soc Psychol Bull. 2016;17(5):475-482. doi:10.1177/0146167291175001

98. McKenna KYA, Bargh JA. Coming out in the age of the internet: identity "demarginalization" through virtual group participation. J Pers Soc Psychol. 1998;75(3):681-694. doi:10.1037/00223514.75.3.681

99. Naslund JA, Aschbrenner KA, Marsch LA, et al. The future of mental health care: peer-to-peer support and social media. Epidemiol Psychiatr Sci. 2016;25(2):113-122. doi:10.1017/ S2045796015001067

100. Lin X, Kishore R. Social media-enabled healthcare: a conceptual model of social media affordances, online social support, and health behaviors and outcomes. Technol Forecast Soc Change. 2021;166:120574. doi:10.1016/j.techfore.2021.120574

101. Yang E, Kim J, Pennington-Gray L. Social media information and peer-to-peer accommodation during an infectious disease outbreak. J Dest Mark Manage. 2021;19:100538. doi:10.1016/j. jdmm.2020.100538

102. Agius S, Grech A, Grech V. The way in which COVID-19 changed behaviour on social media in Malta. Early Hum Dev. 2020;105255. doi:10.1016/j.earlhumdev.2020.105255

103. Zhao J, Han H, Zhong B, et al. Health information on social media helps mitigate Crohn's disease symptoms and improves patients' clinical course. Comput Human Behav. 2021;115:106588. doi:10.1016/j.chb.2020.106588

104. Tang Z, Miller AS, Zhou Z. et al. Does government social media promote users' information security behavior towards COVID-19 scams? Cultivation effects and protective motivations. Gov Inf $Q$. 2021;101572. doi:10.1016/j.giq.2021.101572

105. Gever VC, Talabi FO, Adelabu O, et al. Modeling predictors of COVID-19 health behaviour adoption, sustenance and discontinuation among social media users in Nigeria. Telemat Inform. 2021;60:101584. doi:10.1016/j.tele.2021.101584

106. Rosenstock IM. Why people use health services. Milbank $Q$. 2005;83(4):Online-only-Online-only. doi:10.1111/j.1468$0009.2005 .00425 . x$ 
107. Carpenter CJ. A meta-analysis of the effectiveness of health belief model variables in predicting behavior. Health Commun. 2010;25 (8):661-669. doi:10.1080/10410236.2010.521906

108. Jones CJ, Smith H, Llewellyn C. Evaluating the effectiveness of health belief model interventions in improving adherence: a systematic review. Health Psychol Rev. 2014;8(3):253-269. doi:10.1080/17437199.2013.802623

109. Castonguay J, Filer CR, Pitts MJ. Seeking help for depression: applying the health belief model to illness narratives. South Commun J. 2016;81(5):289-303. doi:10.1080/1041794X.2016.1165729

110. Worldometer. COVID-19 coronavirus pandemic; 2020. Available from: https://www.worldometers.info/coronavirus/. Accessed March 17, 2021

111. Aman J, Abbas J, Mahmood S, et al. The influence of islamic religiosity on the perceived socio-cultural impact of sustainable tourism development in pakistan: a structural equation modeling approach. Sustainability. 2019;11(11):3039. doi:10.3390/su11113039

112. Mamirkulova G, Mi J, Abbas J, et al. New silk road infrastructure opportunities in developing tourism environment for residents better quality of life. Glob Ecol Conserv. 2020;24:e01194. doi:10.1016/j.gecco.2020.e01194

113. Zhang H, Song H, Wen L, et al. Forecasting tourism recovery amid COVID-19. Ann Tour Res. 2021;87:103149. doi:10.1016/j. annals.2021.103149

114. Mubeen R, Han D, Abbas J, et al. The effects of market competition, capital structure, and CEO duality on firm performance: a mediation analysis by incorporating the GMM model technique. Sustainability. 2020;12(8):3480. doi:10.3390/su12083480

115. Xu B, Gutierrez B, Mekaru S, et al. Epidemiological data from the COVID-19 outbreak, real-time case information. Sci Data. 2020;7(1):106. doi:10.1038/s41597-020-0448-0

116. Su Z, Wen J, Abbas J, et al. A race for a better understanding of COVID-19 vaccine non-adopters. Brain Behav Immun. 2020;9:100159. doi:10.1016/j.bbih.2020.100159

117. Abbas J. Crisis management, transnational healthcare challenges and opportunities: The intersection of COVID-19 pandemic and global mental health. Research in Globalization. In press 2021. doi:10.1016/j.resglo.2021.100037

118. Jahangiri M, Jahangiri M, Najafgholipour M. The sensitivity and specificity analyses of ambient temperature and population size on the transmission rate of the novel coronavirus (COVID-19) in different provinces of Iran. Sci Total Environ. 2020;728:138872. doi:10.1016/j.scitotenv.2020.138872

119. Saqlain M, Munir MM, Ahmed A, et al. Is Pakistan prepared to tackle the coronavirus epidemic? Drugs Ther Perspect. 2020;36 (5):1-2. doi:10.1007/s40267-020-00721-1

120. Abbas J, Aqeel M, Ling J. et al. Exploring the relationship between intimate partner abuses, resilience, psychological, and physical health problems in Pakistani married couples: a perspective from the collectivistic culture. Sex Relatsh Ther. 2020;1-30. doi:10.1080/14681994.2020.1851673
121. Boccaletti S, Mindlin G, Ditto W, et al. Closing editorial: forecasting of epidemic spreading: lessons learned from the current covid-19 pandemic. Chaos Solitons Fractals. 2020;139:110278. doi:10.1016/j.chaos.2020.110278

122. Maqsood A, Abbas J, Rehman G, et al. The paradigm shift for educational system continuance in the advent of COVID-19 pandemic: mental health challenges and reflections. Curr Res Behav Sci. 2021;2:100011. doi:10.1016/j.crbeha.2020.100011

123. Daniel SJ. Education and the COVID-19 pandemic. Prospects. 2020;49(1-2):91-96. doi:10.1007/s11125-020-09464-3

124. Prem K, Liu Y, Russell TW, et al. The effect of control strategies to reduce social mixing on outcomes of the COVID-19 epidemic in Wuhan, China: a modelling study. Lancet Public Health. 2020;5(5):e261-e270. doi:10.1016/S2468-2667(20)30073-6

125. Almarzooq ZI, Lopes M, Kochar A. Virtual Learning During the COVID-19 Pandemic: A Disruptive Technology in Graduate Medical Education. J Am Coll Cardiol. 2020;75(20):2635-2638. doi:10.1016/j.jacc.2020.04.015

126. Khan RA, Jawaid M. Technology enhanced assessment (TEA) in COVID 19 pandemic. Pak J Med Sci. 2020;36(COVID19-S4): S108-S110. doi:10.12669/pjms.36.COVID19-S4.2795

127. Ali MY, Gatiti P. The COVID-19 (coronavirus) pandemic: reflections on the roles of librarians and information professionals. Health Info Libr J. 2020;37(2):158-162. doi:10.1111/hir.12307

128. Anjum MN, Xiuchun B, Abbas J, Shuguang Z, McMillan D. (2017). Analyzing predictors of customer satisfaction and assessment of retail banking problems in Pakistan. Cogent Business \& Management, 4(1), 1338842 . doi: 10.1080 / 23311975.2017.1338842

129. Abbas, J., Mubeen, R., Iorember, P. T., Raza, S., \& Mamirkulova, G. (2021). Exploring the impact of COVID-19 on tourism: transformational potential and implications for a sustainable recovery of the travel and leisure industry. Current Research in Behavioral Sciences, 2, 100033. doi: 10.1016/j.crbeha.2021.100033

130. Bao, Y., Sun, Y., Meng, S., Shi, J., \& Lu, L. (2020). 2019-nCoV epidemic: address mental health care to empower society. The Lancet, 395(10224), e37-e38. doi: 10.1016/S0140-6736(20) 30309-3

131. Jafri LA, Javed M, Sajjad A, Kanwar D, Wasay M. Neurological care and training in the times of covid-19: a tertiary care center experience. Pakistan Journal of Neurological Sciences. 2020;15 (3):4-10.
Risk Management and Healthcare Policy

\section{Publish your work in this journal}

Risk Management and Healthcare Policy is an international, peerreviewed, open access journal focusing on all aspects of public health, policy, and preventative measures to promote good health and improve morbidity and mortality in the population. The journal welcomes submitted papers covering original research, basic science, clinical \& epidemiological studies, reviews and evaluations, guidelines, expert opinion and commentary, case reports and extended reports. The manuscript management system is completely online and includes a very quick and fair peer-review system, which is all easy to use. Visit http://www.dovepress.com/testimonials.php to read real quotes from published authors. 